\title{
Proper Function Justification and Epistemic Rationality
}

\author{
Todd R. Long \\ California Polytechnic State University
}

Drawing on the traditional view that knowledge essentially concerns well-done rational inquiry, many epistemologists take epistemic justification to be extensionally equivalent to epistemic rationality. ${ }^{1}$ Accordingly, to have propositional epistemic justification is to have-one's total epistemic condition considered-good truth-indicating reasons with respect to the proposition, and to have doxastic epistemic justification is to have a doxastic attitude with respect to a proposition based on good truth-indicating reasons. ${ }^{2}$ Michael Bergmann (2006) has introduced a new theory of doxastic justification, which he claims analyzes the very same epistemic property that has concerned leading evidentialists or internalists, whose theories plausibly concern truth-indicating reasons for belief. In what follows I reveal that Bergmann's theory is inapt to secure the suggested justification-rationality equivalence, a result that provides reason to deny that Bergmann's theory is about the same property that has concerned the evidentialists or internalists that he discusses.

Bergmann explicitly takes himself to be discussing the same epistemic property that many leading evidentialists or internalists treat in their theories of epistemic justification:

... my purpose in explaining how I use the term 'justification' is not to strike a conciliatory note by saying: 'while externalism is true of the sort of justification $I$ have in mind, internalism is true of the sort of justification internalists have in mind'. Indeed, I think the sort of justification I'll be highlighting... just is the sort of justification in which many internalists are interested. (Bergmann, 2006, p. 4)

... the justification I'm interested in was shown by Gettier to be insufficient for warrant. ${ }^{3}$ Thus, justification, as I will be thinking of it, is more objective than subjective deontological justification but still insufficient for warrant.... The sort of justification I have in mind ... is viewed by most as necessary but not sufficient for warrant. It certainly isn't the same thing as warrant. (Bergmann, 2006, p. 6, Bergmann's emphasis removed) 
... it is the sort of doxastic justification in which evidentialists like Conee, Feldman, and [Bruce] Russell are interested. (Bergman, 2006, p. 6)

In addition to Earl Conee, Richard Feldman, and Bruce Russell, it is clear from Bergmann's discussion that the extended list (of those epistemologists who are interested in the sort of epistemic justification that Bergmann takes himself to be interested in) also includes (at least) Laurence BonJour, Evan Fales, Richard Fumerton, Timothy McGrew, and Paul Moser. All these evidentialists or epistemic internalists have in common the traditional view, which reaches back at least to the Socrates of Plato's Meno, that the kind of justification that is necessary for knowledge requires having reason to believe. ${ }^{4}$ Because they all take epistemic justification (hereafter, 'justification') essentially to depend on one's having good, objective, truth-indicating reasons, and because Bergmann claims to be analyzing the same concept with which they are concerned, it is both fair and philosophically worthwhile to consider how apt Bergmann's proper function justification theory $\left(\mathrm{J}_{\mathrm{PF}}\right.$ below) is at securing an intimate link between justification and epistemic rationality.

$\mathbf{J}_{\mathrm{PF}}: \mathbf{S}$ 's belief B is justified iff (i) $\mathrm{S}$ does not take $\mathrm{B}$ to be defeated and (ii) the cognitive faculties producing $B$ are (a) functioning properly, (b) truth-aimed and (c) reliable in the environments for which they were 'designed'. (Bergmann, 2006, p. 133)

My investigation depends in part on the fact that $\mathrm{J}_{\mathrm{PF}}$ entails the denial of what Bergmann calls "Necessity."

Necessity: the [epistemic] fittingness of doxastic response B to evidence $\mathrm{E}$ is an essential property of that response to that evidence. (Bergmann, 2006, p. 112)

Bergmann denies Necessity because he thinks that the epistemic fittingness of an input to a belief-forming process can be due to a contingent feature of that input. To illustrate his idea, he discusses two different possible "design plans," where a design plan is the complete description of the natural way of functioning for a cognizer (Bergmann, 2006, Ch. 5). According to "the human design plan," cognizers function properly when they believe B1: there is a smallish hard round object in my hand, as an unlearned causal response to having "main evidence" ME1: tactile sensations of the type you experience when you grab a billiard ball. According 


\section{Proper Function Justification and Epistemic Rationality}

to "design plan B," cognizers function properly when they believe B1 as an unlearned causal response to having "main evidence" ME2: olfactory sensations of the type you experience when you smell a meadow full of flowers.

His argument against Necessity in a nutshell: (i) there is nothing about the ME2-to-B1 process that makes it "intrinsically less suitable (as a natural unlearned process for a cognizer to undergo)" than the ME1-to-B1 process (Bergmann, 2006, p. 119); hence, (ii) it is just as doxastically fitting for the cognizer under design plan B to form B1 as described as it is for the cognizer under the human design plan to form B1 as described; hence, (iii) the epistemic fittingness of an input to a belief-forming process can be due to a contingent feature (i.e., the design plan, which can vary across cognizers) of that input.

For the present purpose, we should focus on the inference from (ii) to (iii) with an eye to discerning whether the doxastic fittingness mentioned in (ii) is sufficient for the kind of epistemic fittingness-mentioned in (iii) - that is suitable for epistemically rational belief. To be fair, our tests should bear in mind the details of $\mathrm{J}_{\mathrm{pF}}$, which Bergmann says is consistent with, and partly motivated by, his denial of Necessity. Consider the following test cases.

Suppose that there exists a powerful and knowledgeable Humean 'infant deity' (Zed), who has created cognizers who are approximately as intelligent as humans. ${ }^{5}$ Although Zed is an immature deity whose created world falls far short of a best possible world, Zed, having recently been infuriated by the deceptions of his older siblings, has developed a passion for honesty and truth. Consequently, Zed has designed his cognizers reliably to believe truths in various circumstances of the environment in which he has placed them. And, due to his youthful vanity, Zed has designed those cognizers such that their happiness depends in part on their believing that Zed exists. Accordingly, the 'Z-design plan' calls for Zed's created cognizers to form belief B2 (there exists a powerful creator, and flying monkeys guard the approach to the wicked witch of the west's house), as an inference from their belief that $p$ (I'm experiencing ME2) and their belief that $q$ (if $\mathrm{p}$, then there exists a powerful creator and fying monkeys guard the approach to the wicked witch of the west's house). The cognizers are designed to believe $p$ and $q$ upon physical contact with another Z-designed cognizer, and they are designed not to notice that they have no reason to believe that appreciating the content of $q$ 's antecedent provides a good reason to believe $q$ 's consequent (in contrast with the fact that they are designed to appreciate, say, that Rex is running unaided gives them reason to believe that Rex has legs); accordingly, they don't take themselves to 
have a defeater for $q$ (just as it is with $p$ ). Also, the cognizers have no reason to believe that flying monkeys guard the approach to the wicked witch of the west's house (i.e., it does not seem to them that they have sensory experience of flying monkeys, or that they have heard testimony about flying monkeys, etc.). Nevertheless, Zed has a reason for the cognizers to believe in flying monkeys and a wicked witch's house: such beliefs are designed to have a salutary role in their unconscious dreams, providing some psychological aid in their struggles against the hardship and suffering that Zed predicts they will endure due to details of the particular world Zed has designed and created. Suppose further that $p, q$, and the proposition expressed by $\mathrm{B} 2$ are all true in the world envisioned whenever a cognizer in that world believes those propositions. Having frequent contact with others, these cognizers frequently engage in a belief-forming inference from ( $p$ and $q$ ) to the content of B2, forming B2 on the basis of that inference. The cognitive faculties producing those beliefs are successfully aimed at truth, for those faculties are likely to produce true beliefs when operating in the environment for which they were designed.

Suppose that one Z-designed cognizer, Spam, has just formed B2 as described and that, for reasons discussed above, Spam's relevant cognitive faculties are functioning as designed, are truth-aimed, are reliable in the environments for which they were designed, and Spam does not take B2 to be defeated. $\mathrm{J}_{\mathrm{PF}}$ implies that Spam's belief B2, as well as his belief that $p$ and his belief that $q$, are epistemically justified.

But, are they epistemically rational? Clearly, Spam lacks a good truthindicating reason to believe that $q$. Spam's method in forming that belief is intellectually poor with respect to the aim of rational inquiry, for it has nothing to do with Spam's reasons, even if he cannot help it and it gets him onto the truth. No doubt Spam's belief that $q$ is the result of some kind of doxastic proper function, for Spam forms that belief just as he was designed to do; but, it does not follow, nor is it at all plausible, that the belief is rational (i.e., "of or based on reasoning or reason"), ${ }^{6}$ much less epistemically rational. And, although Spam's belief B2, being the result of an inference, can be said to have been formed on the basis of reasoning, B2 is epistemically irrational, since Spam literally has no reason to believe the content of B2.?

Now consider another Z-designed cognizer, Bam, who comes to realize that she has no reason to think that the truth of $q$ 's consequent is connected to the truth of $q$ 's antecedent; and, as a result, Bam suspends judgment on not- $q$ and, on that basis, suspends judgment on the content of B2. It seems that Bam is reasoning well, and this suggests that her doxastic attitude toward the proposition expressed by B2 is epistemically ratio- 
nal. ${ }^{8}$ Now, Bergmann would insist that we also consider whether Bam's realization is consistent with the defeater system part of the Z-design plan (see (Bergmann, 2006, chap. 6, especially pp. 170-172)). So, suppose that Bam's realization is not consistent with the Z-design plan's defeater system. That defeater system is designed not to produce suspension of judgment with respect to not- $q$ in Bam's environment, and it is designed not to produce suspension of judgment on the content of B2 in Bam's environment. It follows that Bam is not functioning as designed. Thus, her doxastic attitudes toward $q$ and the content of B2 are, according to $J_{P F}$ unjustified. Nevertheless, these doxastic attitudes strike us as entirely reasonable, and I do not think that this is due to human species chauvinism. I think it is due to an intuition motivating Necessity. Necessity tracks our sense that there are essentially good ways of reasoning and essentially bad ways of reasoning, from the point of view concerned with epistemic rationality. The good ways of reasoning do not become bad if one's design plan fails to sanction them, and the bad ways of reasoning do not become good if one's design plan sanctions them. But, since $\mathrm{J}_{\mathrm{PF}}$ implies otherwise, it is inapt at securing an extensional equivalence of epistemically rational belief and epistemically justified belief.

I do not mean to suggest that all the evidentialist or internalist theories that Bergmann discusses are equally apt at securing the equivalence at issue. However, since they are committed to Necessity (or something very similar) and because they all have to do with what can plausibly be regarded as having reasons, they are much better suited to secure a satisfying relation between justification and rationality than is $\mathrm{J}_{\mathrm{PF}}$

In any case, the evidentialist or internalist theories all share an idea that their proponents think of as central, and thus indispensable, to their respective theories: one's holding a justified belief essentially depends on one's having a good, truth-indicating reason with respect to the believed proposition. But, as I have shown, Bergmann's proper function justification theory does not entail that one's holding a justified belief depends on one's having a good, truth-indicating reason. This result provides reason to deny Bergmann's claim that his theory is concerned with the same property with which the evidentialists or internalists that Bergmann discusses are concerned. ${ }^{9}$ 


\section{Notes}

1 The extensional equivalence amounts to the claim that every instance of epistemically justified belief is an instance of epistemically rational belief, and vice versa. Although among the evidentialists or internalists that Bergmann discusses there is some divergence with respect to the standard of justification that they discuss (e.g., some are concerned with knowledge-level justification, whereas others are concerned with a lower standard of justification yielding positive epistemic status), they tend to have in common the view that whatever various standards there are for epistemic justification track whatever various standards there are for epistemic rationality. The basic idea is that the better epistemic justification one has, the better truth-indicating reason(s) one has, and vice versa.

2 These claims are consistent with the plausible view that suspending judgment can be the doxastic attitude that is epistemically justified for a person; for, in such a case, one's good truth-indicating reasons for a proposition $p$ are roughly on a par with one's good truth-indicating reasons for not- $p$.

3 Bergmann follows Plantinga in defining warrant as that which turns true belief into knowledge, and Bergmann follows many of the paradigm evidentialists or internalists that he discusses in thinking that knowledge is justified true belief plus the satisfaction of a condition to deal with Gettier cases.

4 According to Plato's Meno [97e] Socrates says that the difference between true belief and knowledge is "[giving] an account of the reason why" (Plato, 2002, p. 90).

5 See Hume (1993, Part V), where his commentary suggests that this much of my imaginary creation-and-design story is consistent with what we know of our own world and its human cognizers.

6 This is the first definition or 'rational' in the Oxford English Reference Dictionary. See Pearsall and Trumble (1996, p. 1198).

7 Spam may feel impelled to believe the content of B2, but a feeling of impulsion is not itself a truth-indicating reason. For discussion of this point, see Long (forthcoming), Conee (1998), and Conee and Feldman (2004, pp. 64-67).

8 For other examples that trade on a distinction between proper function and good epistemic function, see Feldman (2003, pp. 103-104), whose examples are directed at Plantinga's reliabilist proper function theory.

9 I do not claim here to have proven that Bergmann's theory concerns a different property than the one with which evidentialists or internalists have been concerned. Anything approaching proof would require providing reason to think that some nonexternalist theory of justification is theoretically preferable to Bergmann's externalist theory, taking into account Bergmann's objections to nonexternalist theories. This is a task 1 take up in my "Mentalism Vindicated (and a SuperBlooper Problem for Proper Function Justification)" (currently unpublished). 


\section{Proper Function Justification and Epistemic Rationality}

\section{Works Cited}

Conee, Earl. (1998) Seeing the Truth. Philosophy and Phenomenological Research 58: 847-857.

Conee, Earl and Richard Feldman. (2004) Internalism Defended. In Earl Conee and Richard Feldman (eds.), Evidentialism: Essays in Epistemology (pp. 53-82). Oxford: Oxford University Press.

Bergmann, Michael. (2006) Justification Without Awareness: A Defense of Epistemic Externalism. Oxford: Clarendon Press.

Feldman, Richard. (2003) Epistemology. Upper Saddle River, NJ: Prentice Hall.

Hume, David. (1993) Dialogues Concerning Natural Religion. In Antony Flew (ed.), David Hume: Writings on Religion (pp. 83-292). La Salle, IL: Open Court.

Long, Todd R. (forthcoming) A Proper De Jure Objection to the Epistemic Rationality of Religious Belief. Religious Studies 46.

Pearsall, J. and B. Trumble (eds.) (1996) The Oxford English Reference Dictionary, $2^{\text {nd }}$ ed. Oxford: Oxford University Press.

Plato. (2002) Meno. In Five Dialogues, $2^{\text {nd }}$ ed., G.M.A. Grube (trans.) (pp. 58 92). Indianapolis, IN: Hackett. 